\title{
Insomnia and its association with absenteeism: A cross-sectional study among Iranian nursing team
}

\author{
Khosro Sadeghniiat-Haghighi \\ Arezu Najafi ${ }^{1}$ \\ Sahar Eftekhari ${ }^{2}$ \\ Samareh Tarkhan ${ }^{2 *}$
}

${ }^{1}$ Tehran University of Medical Science, Occupational sleep research center - Tehran - Iran.

${ }^{2}$ Tehran University of Medical Science, Center for Research on Occupational Disease - Tehran - Iran.

\footnotetext{
*Corresponding author:

Samareh Tarkhan

E-mail: samareh.tarkhan.15@gmail.com
}

Received: September 29, 2020;

Accepted: January 25, 2021.

DOI: $10.5935 / 1984-0063.20200106$

\begin{abstract}
Objective: Given the potential impact of insomnia on nurses' performance, it is assumed that insomnia is associated with their absence from work. The present study aimed to determine the insomnia status and its association with absenteeism among a selective group of Iranian healthcare providers. Material and Methods: This cross-sectional study was conducted on 304 healthcare providers working at Imam-Khomeini hospital complex in Tehran. The study population were assessed by insomnia severity index for characterization of insomnia symptoms. The data of absenteeism was collected from the employees' attendance system of hospital's nursing and staff department. The multivariable linear regression model used for predicting determinants of insomnia and absenteeism in nursing team. Results: Different degrees of insomnia was found in $79.9 \%$ of the study population, which $57.2 \%$ suffered from mild insomnia, $21.4 \%$ from moderate insomnia, and $1.3 \%$ from severe insomnia. The prevalence of insomnia was significantly higher in persons who were absent from their workplace frequently, or left because of illness. The mean days for total absenteeism in healthcare workers with moderate to severe insomnia was significantly higher than others with mild and no insomnia. In multivariate analysis, having night shifts and the severity of insomnia could predict absenteeism in studied population. Discussion: A majority of healthcare workers suffer from insomnia that may lead to their work absenteeism and decreased performance. Proper administrative and individuals for management of sleep problems is required to avoid long hours of absenteeism among nursing team.
\end{abstract}

Keywords: Insomnia; Healthcare provider; Nursing team; Absenteeism. 


\section{INTRODUCTION}

Sleep and rest are one of the basic human needs and are in the series of Maslow's needs in the line of physiological requirements ${ }^{1}$. Other physiological functions of the body may also change when the sleep-wake cycle is disrupted. Sleep deprivation can lead to fatigue, anorexia nervosa, loss of concentration, exacerbation of illness, and physical discomfort ${ }^{2}$. As a result of sleep deprivation, the hormone adrenaline enters the bloodstream more and more, so the person feels tired and depressed, and his or her concentration also decreases ${ }^{3}$. Common sleep-disordersrelated complications include increased cardiovascular disease, gastrointestinal disorders, mental disorders such as depression and anxiety, decreased proper functioning, increased drowsiness, and the occurrence of occupational and non-occupational errors, and even the tendency to take medication ${ }^{4,5}$.

Nurses are the largest professional group in the healthcare system including $40 \%$ of all hospital staff and $55 \%$ of the total staff $\operatorname{costs}^{6}$. Therefore, they play a significant role in the healthcare system. Nurses are one of the most prominent groups in shift work, and the occurrence of insomnia and sleep disorders not only affects their health but also endangers the health of patients under their supervision ${ }^{7,8}$. Sleep disorder is one of the most important factors that reduce the quality of nurses' performance and cause errors in the treatment of patients and can cause irreparable damage.

Absence from work or absenteeism is one of the indicators affected by sleep status and faces the individuals with many problems, especially among nursing and other healthcare providers. Absenteeism is defined as "allocating time to non-work activities when the person is expected to be working". Of course, absenteeism not only means the physical absence of individuals, but also the absence of psychological presence or the ineffective presence and inefficiency of individuals. There are different types of absenteeism, including short-term absenteeism, longterm medical absenteeism, unauthorized or persistent delays, and authorized absenteeism ${ }^{10}$. Absenteeism is also seen as a sign of resignation, as individuals try to avoid negative working conditions by doing negative things such as absenteeism ${ }^{11}$.

Absence from work in the nursing staff causes other people to bear the extra burden, which in turn causes fatigue and job dissatisfaction among them ${ }^{12}$. In addition, absenteeism reduces the quality and quantity of nursing care and ultimately reduces community health ${ }^{13,14}$. The high rate of absenteeism also undermines the minimum care available to patients and clients and threatens the health of society as a whole. The lack of each nurse in his or her position in terms of providing medical services has had an adverse effect on the entire scientific management system and has disrupted the healthcare system, the effect of which is directly on the patients' health ${ }^{15}$. Long and frequent absences from work will eventually lead to leaving work and career. Although nurses' absenteeism may have some benefits such as the withdrawal of dissatisfied, demoralized, or sick workers who are unable to work, and is primarily economically beneficial to the organization, if material costs and management problems are considered which is a very small advantage ${ }^{16}$. This will impose a lot of material costs on hiring and retaining nursing services, spending more time and money to train people to replace employees who are out of service or absent from work.

Given the potential impact of insomnia on nurses' performance, it is assumed that insomnia in this group of healthcare providers is associated with their absence from work. Thus, due to limited information in this regard we aimed to assess the insomnia characteristics among nursing team and to determine whether there is an association between insomnia and work absenteeism.

\section{MATERIAL AND METHODS}

\section{Study population}

This cross-sectional study was conducted on 304 healthcare provider including nurses, head nurses, paramedics and operating room technician, working at Imam Hospital complex, in Tehran, between 2017 and 2019. Stratified sampling and simple random sampling techniques were used to determine the study population. The employees were stratified into 3 major ward including internal ward, surgical ward and intensive care wards (CCU, ICU, and NICU) as well as some minor wards entitled "other wards". The participants were selected from the list of nursing team of each wards using simple random sampling.

A total of 370 questionnaires were distributed between the nursing team of different wards and 304 questionnaires were completed and analyzed. After approval the implementation stages of the project in the ethics committee of the Tehran University of Medical Sciences and providing full explanations to the nurses about the objectives of the study, the investigation was started. Initial information from the nurses, including data on demographic characteristics and their job descriptions was collected through interviews. The data of absenteeism was collected from the employees' attendance system of hospital's nursing and staff department. The following definitions were used for calculating this data:

- Unauthorized absence is when the employee does not come to work and does not contact the employer or gives no reason for his/her absence;

- Sick absence is paid time off from work that workers can use to stay home to address their health needs without losing pay;

- Vacation means the time allotted by the employer for the employees to not be present at work;

- Total absence is total absence days from work (for authorized and unauthorized reasons).

\section{Study measurements}

In a study by Sadeghniiat et al. $(2015)^{17}$, the validity and reliability of the Persian version of the questionnaire is approved. For assessing the severity of insomnia, the insomnia severity index was employed. The insomnia severity index (ISI) is a 7-item self-report questionnaire assessing the nature, severity, and impact of insomnia. The usual recall period is the "last month" and the dimensions evaluated are: severity of sleep onset, sleep maintenance, and early morning awakening problems, sleep 
dissatisfaction, interference of sleep difficulties with daytime functioning, noticeability of sleep problems by others, and distress caused by the sleep difficulties. A 5-point Likert scale is used to rate each item $(0=$ no problem; $4=$ very severe problem $)$, yielding a total score ranging from 0 to 28 . The total score is interpreted as follows: absence of insomnia (0-7); sub-threshold insomnia (8-14); moderate insomnia (15-21); and severe insomnia $(22-28)^{18}$. Yazdi et al. (2012) ${ }^{19}$ demonstrated high reliability and validity of the ISI by the Cronbach's alpha coefficient above 0.8 and intra-class correlation coefficient above 0.7 . The absence data of the nursing team included unauthorized absence, sick absence as well as vacation days and hours in a time period of 30 months.

\section{Statistical analysis}

The results are presented as mean \pm standard deviation (SD) for quantitative variables and were summarized by absolute frequencies and percentages for categorical variables. Quantitative variables were also compared with t test or Mann-Whitney $U$ test and one-way ANOVA. For the statistical analysis, the statistical software SPSS version 22 for windows (SPSS Inc., Chicago, IL, USA) was used. The $p$ values of 0.05 or less were considered statistically significant; $p$ for trend was used to test a linear trend of absenteeism rate between the categories of insomnia grading. The multivariable linear regression model used for predicting determinants of insomnia and absenteeism in nursing team.

\section{RESULTS}

In total, 304 healthcare workers were assessed, with the average age of $35 \pm 8.38$ years. The mean times for unauthorized absence, vacation, and sick absence were $0.35 \pm 0.88,42.39 \pm 23.8$, and $8.30 \pm 37.1$ days per 30 months, respectively (Table 1).

Overall, 46.1\% went to bed at midnight. Real sleep hours less than 5 hours were expressed by $19.4 \%$. The use of sedatives or hypnotics for sleeping was once per week in $6.6 \%$, twice weekly in $2.3 \%$ and three times or more per week in $2.6 \%$. Regarding difficulties in sleeping, severe to very severe impairment in falling asleep, staying asleep, and in waking up very early was expressed by $9.6 \%, 10.9 \%$, and $13.1 \%$, respectively. Also, $21.0 \%$ of the nursing team were dissatisfied or had very little satisfaction. $53 \%$ percent believed that sleep difficulty interferes severely with their daily activities. In addition, $29.0 \%$ also found that quality of life could be disturbed by sleep difficulties. Also, $23.4 \%$ were very worried about their sleep (Table 2).

Overall, the mean ISI score was $11.26 \pm 4.26$ in total, different degrees of insomnia was found in $79.9 \%$ of the study population that $57.2 \%$ suffered from subthreshold insomnia (8-14), 21.4\% from moderate insomnia (15-21), and 1.3\% from severe insomnia (22-28). With regard to the relationship between the severity of insomnia based on the ISI score and baseline variables, women had higher ISI score compared to men (11.60 \pm 4.24 vs. $9.88 \pm 4.10, p=0.006$ ); but, the severity of insomnia was independent to other parameters including age, marital status, education level, body mass index, overtime working, workplace (wards of hospitals), the presence of second or third job, underlying disease or use of medications, smoking, and distance
Table 1. Baseline and work characteristics of study population (304 healthcare providers).

\begin{tabular}{|c|c|}
\hline Mean age, year & $35.00 \pm 8.38$ \\
\hline Gender, female & $247(81.3 \%)$ \\
\hline Marital status, married & $167(55.0 \%)$ \\
\hline \multicolumn{2}{|l|}{ Education level } \\
\hline \multicolumn{2}{|l|}{ Master } \\
\hline \multicolumn{2}{|l|}{ Bachelor } \\
\hline Under Bachelor & $35(11.6 \%)$ \\
\hline \multicolumn{2}{|l|}{$235(77.6 \%)$} \\
\hline \multicolumn{2}{|l|}{$33(10.8 \%)$} \\
\hline Having child & $114(37.5 \%)$ \\
\hline Underlying disease & $48(15.8 \%)$ \\
\hline Using different drugs & $18(5.9 \%)$ \\
\hline Smoking & $48(15.8 \%)$ \\
\hline Mean (SD) number of children & $0.58 \pm 0.85$ \\
\hline Mean (SD) job experience, year & $10.01 \pm 7.14$ \\
\hline Mean (SD) overtime work, hour & $82.01 \pm 43.88$ \\
\hline Mean (SD) body mass index, $\mathrm{kg} / \mathrm{m}^{2}$ & $24.82 \pm 3.91$ \\
\hline Mean (SD) systolic blood pressure, $\mathrm{mmHg}$ & $111.16 \pm 11.49$ \\
\hline Mean (SD) diastolic blood pressure, $\mathrm{mmHg}$ & $69.30 \pm 9.00$ \\
\hline Mean (SD) distance from work place, $\mathrm{km}$ & $25.82 \pm 27.38$ \\
\hline \multicolumn{2}{|l|}{ Task } \\
\hline Head nurse & $12(4.1 \%)$ \\
\hline Nurse & $243(82.4 \%)$ \\
\hline Paramedic & $33(11.2 \%)$ \\
\hline Operating room technician & $7(2.3 \%)$ \\
\hline \multicolumn{2}{|l|}{ Workplace (ward) } \\
\hline Internal & $61(21.2 \%)$ \\
\hline Surgery & $76(26.5 \%)$ \\
\hline CCU \& ICU \& NICU & $64(22.3 \%)$ \\
\hline Others & $86(30 \%)$ \\
\hline Having shift work & $273(89.8 \%)$ \\
\hline \multicolumn{2}{|l|}{ Types of shifts: } \\
\hline Only morning & $31(10.6 \%)$ \\
\hline Only night & $24(8.1 \%)$ \\
\hline Morning/evening & $78(26.4 \%)$ \\
\hline Morning/evening/night & $136(46.1 \%)$ \\
\hline Evening/night & $26(8.8 \%)$ \\
\hline Having second job & $37(12.2 \%)$ \\
\hline Having third job & $2(0.7 \%)$ \\
\hline Mean (SD) time for unauthorized absence, days & $0.35 \pm 0.88$ \\
\hline Mean (SD) time for vacation, days & $42.39 \pm 23.80$ \\
\hline Mean (SD) time for sick absence, days & $8.30 \pm 3.11$ \\
\hline
\end{tabular}

between home to workplace. There was no association between the type of work shift and the presence of insomnia $(p=0.19)$.

The prevalence of insomnia was significantly higher in the healthcare providers who were absent from their workplace frequently, or left there because of illness. The $p$ for trend was used to test a linear trend of absenteeism rate between 3 categories of insomnia grading (no insomnia, mild insomnia, and moderate to severe insomnia). In this regard, the mean days for unauthorized absenteeism in persons with no, mild, moderate to severe insomnia was $0.16 \pm 0.45,0.37 \pm 0.87$, and $0.49 \pm 1.13$ days, respectively ( $\not$-value trend $=0.03)$, the mean time for absenteeism due to illness was also $1.70 \pm 5.04,6.94 \pm 32.8$, and $17.59 \pm 56.96$, respectively ( $p$-value trend $=0.01)$ and the mean time for total absenteeism was $43.3 \pm 17.5$, 49.8 $\pm 44.6,60.9 \pm 62.14$, respectively ( $p$-value trend=0.03) (Table 3). 
Table 2. Difficulties in sleeping among 304 healthcare providers according to scores of 7 items of insomnia severity index.

\begin{tabular}{|c|c|c|c|c|c|}
\hline ISI items score & 0 & 1 & 2 & 3 & 4 \\
\hline 1 Hard to fall asleep ${ }^{1} \mathrm{~N}(\%)$ & $100(32.9)$ & $101(33.2)$ & $74(24.3)$ & $26(8.6)$ & $3(1.0)$ \\
\hline 2 Hard to staying asleep ${ }^{1} \mathrm{~N}(\%)$ & $103(33.9)$ & $97(31.9)$ & $71(23.4)$ & $26(8.6)$ & $7(2.2)$ \\
\hline 3 Waking up very early ${ }^{1} \mathrm{~N}(\%)$ & $111(36.5)$ & $82(27.0)$ & $71(23.4)$ & $28(9.2)$ & $12(3.9)$ \\
\hline 4 Sleep satisfaction ${ }^{2} \mathrm{~N}(\%)$ & $32(10.6)$ & $50(16.4)$ & $158(52.0)$ & $50(16.4)$ & $14(4.6)$ \\
\hline 5 Interfering with daily activities ${ }^{2} \mathrm{~N}(\%)$ & $27(8.8)$ & $34(11.2)$ & $82(27.0)$ & $92(30.3)$ & $69(22.7)$ \\
\hline 6 Interfering with quality of $\operatorname{life}^{2} \mathrm{~N}(\%)$ & $37(12.1)$ & $72(23.7)$ & $107(35.2)$ & $54(17.8)$ & $34(11.2)$ \\
\hline 7 Worry about sleep status ${ }^{2} \mathrm{~N}(\%)$ & $69(22.7)$ & $77(25.3)$ & 87 (28.6) & $55(18.1)$ & $16(5.3)$ \\
\hline
\end{tabular}

Notes: ${ }^{1}$ The score of $0,1,2,3,4$ indicating non, mild, moderate, severe, and very severe, respectively; ${ }^{2}$ The score of $0,1,2,3,4$ not at all, a little, somewhat, much, and very much, respectively.

Table 3. The unauthorized, vacation and sick absenteeism rates in study population and association between absenteeism and insomnia index.

\begin{tabular}{|c|c|c|c|c|c|}
\hline Insomnia severity index & $\begin{array}{l}\text { Unauthorized } \\
\text { absenteeism }^{1} \\
\text { Mean (SD) }\end{array}$ & $\begin{array}{c}\text { Vacation } \\
\text { absenteeism }^{1} \\
\text { Mean (SD) }\end{array}$ & $\begin{array}{l}\text { Sick absenteeism }^{1} \\
\text { Mean (SD) }\end{array}$ & $\begin{array}{l}\text { Vacation and sick } \\
\text { absenteeism }^{1} \\
\text { Mean (SD) }\end{array}$ & $\begin{array}{c}\text { Total } \\
\text { absenteeism }^{1} \\
\text { Mean (SD) }\end{array}$ \\
\hline Total $(\mathrm{N}=304)$ & $0.35 \pm .88$ & $42.39 \pm 23.80$ & $8.31 \pm 37.11$ & $50.70 \pm 45.74$ & $51.05 \pm 45.86$ \\
\hline No insomnia $(\mathrm{N}=61)$ & $0.16 \pm 0.45$ & $41.52 \pm 17.31$ & $1.70 \pm 5.04$ & $43.23 \pm 17.59$ & $43.39 \pm 17.58$ \\
\hline Mild insomnia $(\mathrm{N}=174)$ & $0.37 \pm 0.87$ & $42.51 \pm 25.63$ & $6.94 \pm 32.82$ & $49.44 \pm 44.66$ & $49.81 \pm 44.69$ \\
\hline Moderate to severe insomnia $(\mathrm{N}=69)$ & $0.49 \pm 1.13$ & $42.87 \pm 24.23$ & $17.59 \pm 56.96$ & $60.46 \pm 61.84$ & $60.96 \pm 62.14$ \\
\hline$p$-value trend & 0.03 & 0.75 & 0.01 & 0.03 & 0.03 \\
\hline
\end{tabular}

Notes: ${ }^{1}$ Days in period of 30 months.

Then we used regression analysis to examine if insomnia grading is predictor of absenteeism in nursing team. In a multivariable linear regression analysis, of all baseline variables, gender, number of children, having underlying diseases, and shift type could predict insomnia. On the other side, gender, having second job, having night shifts, and severity of insomnia could predict absenteeism in studied nursing team (Table 4).

Table 4. The multivariable linear regression model for predicting determinants of insomnia and absenteeism among nurses.

\begin{tabular}{|c|c|c|c|c|}
\hline \multirow{2}{*}{ Variable in model } & \multicolumn{2}{|c|}{ ISI Score } & \multicolumn{2}{|c|}{ Total absenteeism } \\
\hline & $\mathrm{B}$ & Sig & B & Sig \\
\hline Constant & - & 0.21 & - & 0.96 \\
\hline Age & -0.63 & 0.29 & 0.31 & 0.56 \\
\hline Gender & 0.43 & 0.04 & -0.63 & 0.02 \\
\hline Number of children & 0.44 & 0.03 & -0.24 & 0.25 \\
\hline Age of first child & -0.48 & 0.25 & -0.60 & 0.18 \\
\hline Age of second child & 1.03 & 0.09 & 0.34 & 0.56 \\
\hline Smoking & 0.25 & 0.38 & -0.19 & 0.47 \\
\hline Having underlying disease & 0.64 & 0.009 & -0.15 & 0.59 \\
\hline Having Second job & 0.32 & 0.15 & -0.48 & 0.04 \\
\hline Task $^{1}$ & -0.20 & 0.48 & 0.02 & 0.93 \\
\hline Over time work & 0.04 & 0.87 & 0.28 & 0.24 \\
\hline Having shift work & 0.70 & 0.11 & 0.85 & 0.08 \\
\hline Shift type ${ }^{2}$ & -1.25 & 0.04 & -1.29 & 0.06 \\
\hline Night shift & -0.20 & 0.40 & 0.93 & 0.004 \\
\hline Insomnia grading & - & - & 0.80 & 0.02 \\
\hline Model R square & \multicolumn{2}{|c|}{0.56} & \multicolumn{2}{|c|}{0.63} \\
\hline
\end{tabular}

Notes: ${ }^{1}$ Tasks including: nurses, head nurses, paramedics and operating room technician; ${ }^{2}$ Shift type: only morning, only night, morning \& evening, morning \& evening \& night, evening \& night.

\section{DISCUSSION}

Long-term absence from work or repeated absenteeism is a serious risk profile for permanently leaving the job, which leads to the loss of an efficient and experienced workforce. Proper job performance is the result of a combination of physical and mental health factors and it is obvious that with mastery of different underlying physical and mental disturbances, the likelihood of permanent absenteeism can be increased. In this regard, it is now suggested that insomnia (that is on its own the result of the high workload and poor quality of the community health management system) is closely linked to absenteeism among healthcare providers. Furthermore, in this study, absenteeism among nursing team is strongly associated with the severity of insomnia even after adjusting baseline demographic and work-related factors. In other words, high workload among the nursing team can lead to sleep disorders. Having feeling of sleepiness and discomfort in work environment reduces the quality of service delivering to patients and increases risk of occupational errors occurrence. Moreover, it leads to a tendency for long vacations, even temporary and sometimes leaving the workplace permanently. Of course, it should be noted that the population of nursing team who included in this study work in a referral hospital in Tehran and all of them lived in Tehran, which is known as one of the busiest cities in the world. Ultimately, the triangle of workload, the living environment, and sleep disorders will all lead to nursing teams' absenteeism and ultimately the desire to leave the workplace.

As indicated similarly by Lamont et al. $(2017)^{20}, 44 \%$ of the nurse and midwife respondents took sickness absence and in this regard, those affected were significantly more likely to be at younger ages, working shifts with less time sitting at work, to report workplace abuse and plans to leave, to be current smokers, 
to report mental health problems, accomplishing less due to emotional problems, and current psychotropic medication use.

The physiological function and rhythm of the body's circulatory system changes by working in hours outside the designed window (between 6 and 18 hour), which disrupts the secretion of body hormones including cortisol and aldosterone enzymes and ultimately leads to sleep disorders and other adverse health effects in shift workers ${ }^{21}$. In addition, working on shifts results in feeling of moodiness by inducing a decrease in serotonin, a substance that regulates sleep, promotes good mood, and is released during the night ${ }^{22}$. As shown by Chiang et al. (2012) ${ }^{23}$, working tenure has also been found to be a significant predictor of stress levels, depression, and intention to leave nursing. Portela et al. $(2015)^{24}$ showed that the prevalence of insomnia symptoms was $34.3 \%$ and job strain was associated with increased odds for insomnia symptoms; the same result was observed with the combination of emotional demands and low job control. In a similar study by Hui et al. (2015) ${ }^{25}$, those nurses who had higher levels of sleep disturbance were more likely to be absent from work, have lower work performance ratings, and have higher healthcare costs and thus as similarly concluded in our study, more trouble sleeping was significantly related to negative changes in longer absence from work. Bültmann et al. $(2013)^{26}$ found that sleep disturbances and fatigue significantly predicted sickness absences. Rahkonen et al. (2012) ${ }^{27}$ also found that frequent sleep problems were associated with increased sickness absences, both short and long in duration.

Findings of this study revealed there is a linear trend of absenteeism rate including unauthorized absenteeism, sick absenteeism and total absenteeism between 4 categories of insomnia grading ( $p$-value for trend $<0.05$ ). Therefor by developing screening programs, subthreshold insomnia among nursing team can be identified. Then implementation of some effective interventions such as education of sleep hygiene principles and shift scheduling modifications can prevent from adverse outcomes of moderate and severe insomnia.

In total, according to the literatures, it seems that the employees' sleep disturbances can be associated with a wide variety of negative occupational outcomes such as absenteeism and decreased productivity. The absence of nurses results in staff shortages and an additional workload on their colleagues. In addition, absenteeism can be a significant predictor of future and long-term absenteeism and permanent work leave ${ }^{28,29}$. This issue will be clearly detrimental to the organization of hospitals and the quality of patients care in long term. Employee turnover imposes higher costs to the hospital organization including recruiting and training expenses and some hidden costs such as productivity loss, workplace safety issues. Therefore, managerial discussion on absenteeism is clearly warranted.

\section{CONCLUSION}

In conclusion, a majority of nursing team suffer from insomnia that may lead to their reluctance to continue their continuous and quality work activities, which also leads to long vacations, sick leaves, or even a full-time job leaving. Considering the importance of this subject, it is worth focusing on shift scheduling modifications education of sleep hygiene principles to help alleviate the burden of insomnia among nursing team.

\section{ACKNOWLEDGMENT}

We would like to thank all the nurses who contributed in this survey.

\section{REFERENCES}

1. Henwood BF, Derejko KS, Couture J, Padgett DK. Maslow and mental health recovery: a comparative study of homeless programs for adults with serious mental illness. Adm Policy Ment Health. 2015 Mar;42(2):220-8.

2. Riemann D, Baglioni C, Bassetti C, Bjorvatn B, Groselj LD, Ellis JG, et al. European guideline for the diagnosis and treatment of insomnia. J Sleep Res. 2017 Dec;26(6):675-700.

3. Winkelman JW. Insomnia disorder. N Engl J Med. 2015 Oct;373(15):1437-44.

4. Yang B, Wang Y, Cui F, Huang T, Sheng P, Shi T, et al. Association between insomnia and job stress: a meta-analysis. Sleep Breath. 2018 Dec;22(4):1221-31.

5. Sánchez-Cárdenas AG, Navarro-Gerrard C, Nellen-Hummel H, HalabeCherema J. Insomnia. A severe healthcare problem. Rev Med Del Inst Mex Seguro Soc. 2016;54(6):760-9.

6. Trinkoff A, Geiger-Brown J, Brady B, Lipscomb J, Muntaner C. How long and how much are nurses now working? Too long, too much, and without enough rest between shifts, a study finds. Am J Nurs. 2006 Apr;106(4):60-71.

7. Sandlund C, Hetta J, Nilsson GH, Ekstedt M, Westman J. Impact of group treatment for insomnia on daytime symptomatology: Analyses from a randomized controlled trial in primary care. Int J Nurs Stud. 2018 Sep;85:126-35.

8. Kousloglou SA, Mouzas O, Bonotis K, Roupa Z, Vasilopoulos A, Angelopoulos N. Insomnia and burnout in Greek Nurses. Hippokratia. 2014 Apr/Jun;18(2):150-5.

9. Alexanderson K, Norlund A. Aim, background, key concepts, regulations, and current statistics. Scand J Public Health Suppl. 2004;32:12-30.

10. Hill JJ, Slade MD, Cantley L, Vegso S, Fiellin M, Cullen MR. The relationships between lost work time and duration of absence spells: proposal for a payroll driven measure of absenteeism. J Occup Environ Med. 2008 Jul;50(7):840-51.

11. Pęciłło M. Selected aspects of absence at work and work-related health problems in Polish enterprises. Int J Occup Saf Ergon. 2015;21(3):268-75.

12. Roelen CA, Van Hoffen MF, Waage S, Schaufeli WB, Twisk JW, Bjorvatn $\mathrm{B}$, et al. Psychosocial work environment and mental health-related longterm sickness absence among nurses. Int Arch Occup Environ Health. 2018 Feb;91(2):195-203.

13. Baydoun M, Dumit N, Daouk-Öyry L. What do nurse managers say about nurses' sickness absenteeism? A new perspective. J Nurs Manag. 2016 Jan;24(1):97-104.

14. Castle NG, Ferguson-Rome JC. Influence of nurse aide absenteeism on nursing home quality. Gerontologist. 2015 Aug;55(4):605-15.

15. Unruh L, Joseph L, Strickland M. Nurse absenteeism and workload: negative effect on restraint use, incident reports and mortality. J Adv Nurs. 2007 Dec;60(6):673-81.

16. Li H, Cheng B, Zhu XP. Quantification of burnout in emergency nurses: a systematic review and meta-analysis. Int Emerg Nurs. 2018 Jul;39:46-54.

17. Sadeghniiat-Haghighi K, Montazeri A, Khajeh-Mehrizi A, Ghajarzadeh M, Alemohammad ZB, Aminian O, et al. The STOP-BANG questionnaire: reliability and validity of the Persian version in sleep clinic population. Qual Life Res. 2015 Aug;24(8):2025-30.

18. Morin CM, Belleville G, Bélanger L, Ivers H. The insomnia severity index: psychometric indicators to detect insomnia cases and evaluate treatment response. Sleep. 2011 May;34(5):601-8.

19. Yazdi Z, Sadeghniiat-Haghighi K, Zohal MA, Elmizadeh K. Validity and reliability of the Iranian version of the insomnia severity index. Malays J Med Sci. 2012 Oct;19(4):31-6.

20. Lamont S, Brunero S, Perry L, Duffield C, Sibbritt D, Gallagher R, et al. 'Mental health day'sickness absence amongst nurses and midwives: workplace, workforce, psychosocial and health characteristics. J Adv Nurs. 2017 May;73(5):1172-81.

21. Reinberg A, Ashkenazi I. Internal desynchronization of circadian rhythms and tolerance to shift work. Chronobiol Int. 2008 Jul;25(4):625-43.

22. Martino MMF, Abreu ACB, Barbosa MFS, Teixeira JEM. The relationship between shift work and sleep patterns in nurses. Ciênc Saúde Coletiva. 2013 Mar;18(3):763-8. 
23. Chiang YM, Chang Y. Stress, depression, and intention to leave among nurses in different medical units: Implications for healthcare management/nursing practice. Health Policy. 2012 Dec;108(2-3):149-57.

24. Portela LF, Luna CK, Rotenberg L, Silva-Costa A, Toivanen S, Araújo $\mathrm{T}$, et al. Job strain and self-reported insomnia symptoms among nurses: what about the influence of emotional demands and social support? Biomed Res Int. 2015;2015:820610.

25. Hui SKA, Grandner MA. Trouble sleeping associated with lower work performance and greater healthcare costs: longitudinal data from Kansas state employee wellness program. J Occup Environ Med. 2015 Oct;57(10):1031-8.
26. Bültmann U, Nielsen MBD, Madsen IE, Burr H, Rugulies R. Sleep disturbances and fatigue: independent predictors of sickness absence? A prospective study among 6538 employees. Eur J Public Health. 2013 Feb;23(1):123-8.

27. Rahkonen O, Lallukka T, Kronholm E, Vahtera J, Lahelma E, Laaksonen M. Sleep problems and sickness absence among middle-aged employees. Scand J Work Environ Health. 2012 Jan;38(1):47-55.

28. Rantanen I, Tuominen R. Relative magnitude of presenteeism and absenteeism and work-related factors affecting them among healthcare professionals. Int Arch Occup Environ Health. 2011 Feb;84(2):225-30.

29. Skagert K, Dellve L, Ahlborg Junior G. A prospective study of managers' turnover and health in a healthcare organization. J Nurs Manag. 2012 Oct;20(7):889-99. 